\title{
GEO-EYE
}

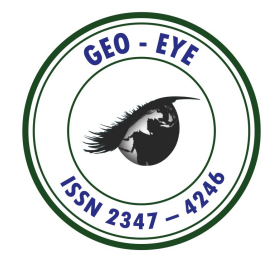

RESEARCH ARTICLE

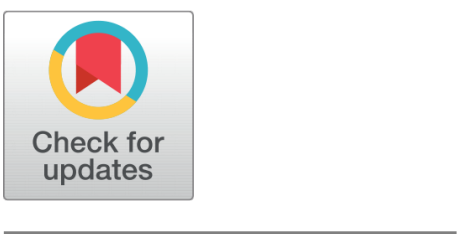

G OPEN ACCESS

Received: 11.02.2020

Accepted: 22.04 .2020

Published: 14.05.2020

Citation: Rambhakta PB. (2020). CULTURAL HERITAGE IN THE CONTEXT OF URBANISING LANDSCAPES: AN OVERVIEW OF URBAN CULTURAL HERITAGE IN INDIAN CITIES. Geo-Eye. 9(1): 4-7. h ttps://doi.org/10.53989/bu.ge.v9i1.2

Funding: None

Competing Interests: None

Copyright: @ 2020 Rambhakta. This is an open access article distributed under the terms of the Creative Commons Attribution License, which permits unrestricted use, distribution, and reproduction in any medium, provided the original author and source are credited.

Published By Bangalore University, Bengaluru, Karnataka

ISSN

Print: 2347-4246

Electronic: XXXX-XXXX

\section{CULTURAL HERITAGE IN THE CONTEXT OF URBANISING LANDSCAPES: AN OVERVIEW OF URBAN CULTURAL HERITAGE IN INDIAN CITIES}

\author{
Pooja Biswas Rambhakta ${ }^{1}$ \\ 1 Ph.D, Centre d'Économie de la Sorbonne (CES), Université Paris 1, Pantheon, Sorbonne, Paris
}

\section{Abstract}

Achieving sustainable development has been a global concern for decades. The urban situation in most developing countries has been chaotic with a fast-paced unregulated developmental boom. In India, the uncontrolled urban advancement has been an outcome of its rapid urbanisation in nearly every city. Consequently, this is leading to the hasty decline in the urban cultural built heritage. This paper, therefore, tries to look into urban (built) heritage in Indian Cities and makes an endeavour to point out how rapid urbanisation and unplanned development can affect the city heritage. Deemed as a fast urbanising Indian city (also a smart city) with evaporating cultural heritage, the research undertook Visakhapatnam as a case study. Urban heritage - Cultural heritage - urbanisation - Vizag heritage - Vernacular-building - Endangered cultural heritage - Urbanisation and conservation - heritage in urbanising societies.

Keywords: Urban heritage; Cultural heritage; Urbanisation; Vizag heritage; Vernacular building; Endangered cultural heritage; Urbanisation conservation heritage in urbanising societies

\section{Introduction}

"Cultural layering is a common feature of most Asian cities...they all tell key stories about key stages in the evolution of societies and cities".

The magnitude at which the built heritage is disappearing is raising enough concerns over the future of the cities, globally, particularly, in the developing countries with rapidly urbanising cities. Urban heritage, at present, is challenged in most Indian cities, due to diverse pressures, from rapid, random and unplanned urbanisation, increasing housing demand, lack of identification of heritage structures, lack of judicial acknowledgement of cultural heritage, lack of awareness, in particular, and the socio-cultural, political and climate changes, in general.

Depletion of urban heritage puts the city's future to the risk of being detached from its humble roots, which is one of the direct threat to sustainable development. Though urbanisation affects urban heritage, in general, the blow on the unrecognised and unidentified vernacular structures is considered critical. This article, therefore, discusses how urban cultural heritage is positioned in urbanising Indian cities of today and ways it affects sustainable development. In doing so, the paper studies the Indian smart city 
Visakhapatnam in a little more detail.

Urbanisation is a natural process of city development and is not detrimental unless unchecked and unplanned. On the other hand, when we talk of urban heritage, mostly it has been found that acceptance and appreciation of heritage usually base on their recognition in society, and this often excludes most of the unlisted structures, one of which is the vernacular built heritage type. Indian culture, which is known for its diversity and secularity, has emerged from the country's historical past, dating back to thousands of years. This cultural diversity thus exhibited in built-format in different corners of the country, of which, the vernacular heritage is the most significant portrayal. Therefore, unsurprisingly nearly every corner of any Indian city thrives with heritage elements, which may range from a colossal Fort to quiet residential neighbourhoods. The vernacular heritage reflected in the old housing stock exists in every Indian city. In few cities, the old districts may be well-knitted, clustered and occupy more physical space that makes them a prominent core. While in others, they may be scattered or have a smaller extent.

Urbanisation is characterised by the physical growth of urban areas and when not planned appropriately, lead to urban sprawl. Menchawy, Hakim et al., (2011), had defined urbanisation as the movement of people from the rural communities to other communities whose activities centres around the tertiary or secondary sectors. With urbanisation the pressure on land manifolds. Usually, in the Indian context, it is observed that the rising demand for space to accommodate the increasing population targets the older neighbourhoods. Such a trend exists because of two main reasons. First, vast expanses of land housing the older housing stocks can accommodate multiple quarters in modern-day construction, thus allowing developers to maximise their profit. Second, many of the old buildings are in dilapidated states, which makes it easier to sell-off at a low price. Hence, the developers and the owners are usually at a 'seemingly' win-win situation from the transformation process (if one overlooks its pitfalls).

UNESCO, in the Nara Seminar on the Development and Integrity of Historic Cities, in 1999, highlighted socioeconomic problems of densely populated historical quarters of urban Asia. The key objective that emerged from the seminar was the condition of cultural heritage in historical inner cities of rapid urbanising developing towns. It emphasised the struggles of depopulating smaller cities, in contrast to the overpopulating big cities that suffered from degenerating quality of life from urban sprawling and urban agglomerations. It pointed out the continual alterations of the historic fabric of the inner-cities, brought about by rapid urbanisation and new preferences; the tendencies of preserving standalone monuments without respecting its setting; the over utilisation of historic sites in the form of tourism without correct measures and lack of maintenance. It was the Nara Seminar that brought about the negative impacts that these big urbanising cities are facing at a socio-economic and cultural level (UNESCO World Heritage Centre, 1999).

In India, the cities contribute to about $2 / 3$ of its economic output. There are 7935 towns with about 1 billion population and 475 urban agglomerations. The rapid expansion of Indian cities is due to rural-urban migration in search of economic opportunity.

Despite some efforts from the local government, urban cultural heritage is being neglected and historic buildings keep being replaced by ordinary concrete buildings at a worryingly rapid pace.

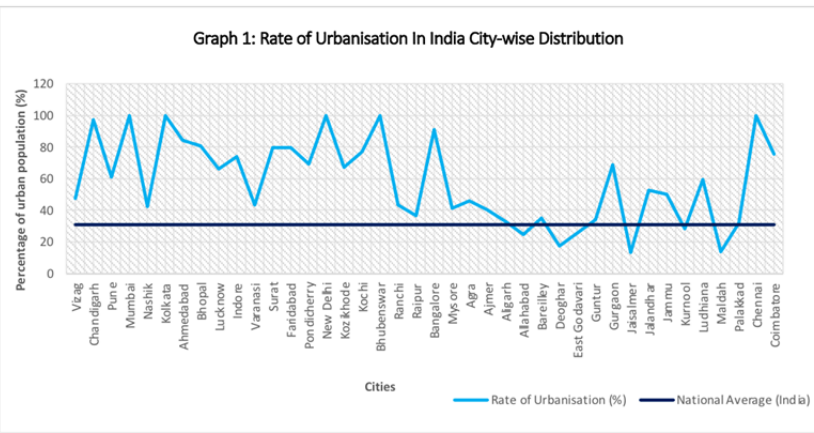

Graph 1: Source: Computed from data available atCensus of India, 2011

Over the next two decades, it is projected to have an increase in population from 282 million to 590 million people (The World Bank). India experienced a sudden urban population explosion in the last five to six decades i.e. postIndependence, which spurred unsupervised, unplanned and random growth in Cities. Such changes were a short-term goal centric, often neglecting the long-term side effect.

The increasing rate of urbanisation has been bringing about a massive change in the land use function and their socio-economic activities. At the national level, mostly the metropolitan cities such as New Delhi, Mumbai, Kolkata, Chennai and Bhubaneswar have $100 \%$ urban population while cities like Pune, Vizag, Nashik, Pondicherry, Ludhiana, Lucknow, Agra, Surat, Bhopal, Indore etc. have above-average urban population while Jaisalmer, Allahabad, Deoghar, Kurnool, East Godavari, Maldah have below average. The level of urbanisation in Andhra Pradesh is 33.49\% in 2011 , which is $6.19 \%$ increase since 2001 . The net addition in urban population during each decade has been increasing with the highest recorded between 2001 and 2011. In absolute terms, the urban population of the state increased by 48,78,634 (as per re-cast data) during 2001-2011 recording $20.78 \%$ decadal growth. Hyderabad district, which was a part of the state of Andhra, continued to be at the top with the highest proportion of urban population followed by Rangareddy (70.32\%), Visakhapatnam (47.51\%) and Krishna 
(41.01\%). The number of towns including Statutory and Census towns in Andhra Pradesh at 2011 Census was 353.

In the case of Visakhapatnam, like almost any other Indian city rise in the percentage of urban population initiated the emergence of urban sprawls that eventually deteriorated the original fabric of the old towns. Urban sprawls mostly started to occur in One Town, which defined the main town centre of the past. It gradually started converting to very highdensity housing with a low supply of basic amenities. Severe air pollution from the coal dust flying from the nearby Port activities along with the lack of necessary infrastructural facilities are reasons aiding in the worsening of the quality of life in this neighbourhood. Usually, as in many other Indian cities slowly, as the city grows, the historic cores turns into inner cities, and the situation has been somewhat similar in Vizag too. Though the essential activities, such as commercial, administrative, and the residential, started to shift to the newer developed parts, the One Town still serves as the commercial centre for specific indigenous goods and services. However, the overall effect of the city growth lately (particularly after the Port activities commenced) is gradually destroying its original built fabric. Although, this phenomenon is not restricted to Visakhapatnam alone but frequent in most Indian cities, including Calcutta, New Delhi etc.

Another trait found in Visakhapatnam is the sudden demand for land that is heightening the dominance of the builders' group who are trying to acquire perfect control and dominance over the city's real estate. These developers, often taking the form of real estate goons, with an extreme commercial outlook, have an ultimate objective, which is to maximise their profit. Often, it is observed, that these medium-sized towns, which are in the threshold of rapid urbanisation and development fall prey to these real estate societies where every inch of land is only seen through a commercial lens and are therefore utilised exhaustively at the cost of all other aesthetic or other cultural values. In such cities, where planning policies and administrative executions are deficient, the historic landscapes are replaced by the high rises of the modern generation, which do not synchronise in the end. The newer developments often stand harsh against the original character of the region. However, in the course of time, with an increase in the new rises, it eventually swallows the existing context such that producing a completely new cultural landscape, which is at the cost of its unique original cultural character.

India is one of the culturally rich countries in the world. However, with the current rate of population influx and urbanisation, much of the cultural landscape is being consumed by modern rises. However, not only in India, this is one of the issues in most developing cities in the world. In China, for instance, where there has been a sudden building boom, branded chiefly by a radical-short term planning and a constant urge to imbibe to the Western-style architecture. In addition to this, the hegemonic power of developers in China, with its characteristically business outlook offered an appropriate combination influencing the creation of the 'mediocre standard' of construction (WHITRAP, UNESCO, 2012).

Consequently, such natures of developments, in these populous cities, along with the thriving population boom are adding on to the existing traffic congestion, air pollution and much other social illness. Cities are growing spatially by creeping into their adjoining smaller towns and villages and gradually engulfing those, creating larger metropolises. These metropolises, in turn, become kind of "museums" representing the tall buildings, which are incoherent to its surroundings (that is its physical and cultural settings). With the progression of such urbanising process in old societies, the cultural sites and old structures initially form small enclaves in the recently-created-foreign-urban-fabric and then eventually get successfully knocked down and concealed by the growing random modern developments. This is a common feature and process, as seen in most of the rapidly urbanising cities of South Asia and Africa. Cities such as Mumbai, Bangalore, and Visakhapatnam (India), Shanghai in China are to name a few.

In Shanghai for instance, as the WHITRAP UNESCO, WHC, 2012, reports about the drastic replacement of the traditional Chinese housing-complexes with high-rise apartment blocks is changing the city's social structure with increasing anonymity, isolation and estrangement. There is a consistent loss of place-attachment amongst fellow Chinese citizens as the result of the fading of its age-old traditions and values.

While hundred years back 2 out of 10 people lived in cities, today as per projection by 2030, 6 out of 10 will live in cities, and by 2050 it is estimated to increase to 7 out of 10. Current urban population is growing by 60 million people every year. Cities are growing at phenomenal rates. Cities like Phnom Penh, Cambodia; Tijuana, Mexico; Marrakesh, Morocco; and Lagos, Nigeria, are expected to continue to grow at annual rates of around $4 \%$, effectively doubling their populations within the next 17 years. Some cities in China, such as Shenzhen and Xiamen, will experience annual growth rates of more than $10 \%$, doubling their populations roughly every seven years.

There are two ways cities are getting affected by the rapid urbanisation. First, while urbanisation is associated with demographic shifts from rural to cities leading to the growth of the urban population. A perpetual increase in city population puts a pressure on it's carrying capacity, which in turn results in increasing demand for limited available land, thus increases the built-up density, both horizontally and vertically. There is an unrelenting urge to demolish the older historical sites (which are usually spread over larger 
space) and convert them to cater to high-density modern apartments. Second, Western architecture is usually seen as a sign of development and of becoming urbane; hence, there is a thriving pressure and tendency to convert old historic sites into modern rises as. Thus, irrespective of the reason the outcome is the conversion of historical heritage sites to modern buildings. Especially, in today's developing cities, where urbanisation is taking places in the most unscientific way, preservation of historic sites is negligible. This process, which has imbibed into a more global form, has taken away the originality and distinctive nature of the culture of each city, making them appear all-same, irrespective of their origin.

Another factor playing an active role in transforming the city fabric of most urbanising Indian cities is the ownership of the buildings. This factor has also been instrumental in bringing about massive changes in most cities in India, and particularly in Vizag. It is easier to convert the functionality of privately owned buildings to any such as multi-storeyed residential complex or malls, theatres, hotels etc. as per need. Thus demolition, renovation is much more convenient. This conversion of old buildings into new ones and changing the face of older neighbourhoods is another evident character of most Indian cities. The following reasons underline the phenomenon more accurately:

1. Usually, old buildings are not in good condition and structurally deteriorating, which is due to low maintenance due to either ignorance or lack of funds.

2. These buildings are spatially spread over larger areas than growing cities can ideally afford. When the horizontal expansion is restricted, vertical development applied.

3. Due to a lack of heritage awareness: only modern buildings are recognised and considered as symbols of development. In several Indian cities, with changing of political hands, promises are made to develop areas by clearing of old housing stock (that are a part of urban sprawl) and replacing them with high rise structures or malls or theatres as a symbol of development.

4. Lack of heritage-based urban management policies

As a result, Developers in these cities can buy these old buildings at low prices and alter them as per-requisite or demolish them and construct new and sell them off at much higher prices. This act is a growing profit-making business, which is gradually changing not only the face of the landscape but also the pattern or function of the land or the land use pattern. Hence, when analysing an urbanising city, the dynamic role of real estate is imperative, especially in Vizag, where the Builders/Developers are very influential.

Such unprecedented urbanisation is a global phenomenon continuing over decades, though the speed at which Asia is developing at present is rapid. The world urban population has increased from 1.35 billion in 1970 to 3.63 billion in
2011. In India, cities are growing dramatically to meet the growing population demand. According to the UN estimates, the current $31 \%$ of the global urban population could increase to $40 \%$ by 2030 , and $70 \%$ by 2050 (Compendium of Good Practice, Urban Heritage in Indian Cities, NIUA, 2015). Even though, until now, heritage conservation is still targeted at the standard and well-known built structure but is expected to change and encompass a more holistic range.

Another feature of Indian cities is its tendency to relate development with modernisation. As a general perception, one of the signs of progress is encouraging modern development in place of the existing old landscape. The case of Varanasi Kashi Project under the current government is one such example. It is the famous heritage site that houses the 18th Century Lord Vishwanath temple on the banks of River Ganges and buildings, many of which are older than the temples itself. To preserve aesthetics and the temple precinct and to aide in smooth tourist flow to the region, the government ordered to destroy the hundreds of old buildings surrounding it. There is an order to vacate the 47,000 sq.m area around the Temple to construct a 50-metre-wide corridor. Such a development activity aimed to provide an obstacle-free view of the Temple for the pilgrims. The government is spending INR 6 billion to get the cultural heritage uprooted from one of India's most iconic temple precinct. The demolished old buildings had a unique feature of having a hidden small Temple set into the recesses of their walls and raised terraces. These have high historical relevance to the Mughal rule.

\section{Conclusion}

While stakes to heritage conservation in growing Indian cities are manifold, there is also tremendous scope for conservation. Since most of the Indian cities are in different phases of development (primarily initial), particularly with the Smart City scheme, a sharp heritage inclusive policy and action plans for development, awareness of urban heritage, identification of urban cultural heritage (that should include the private structures such as the vernacular buildings), and involvement of private authorities through P-P-P will be very instrumental in achieving sustainable development.

\section{References}

1) Lung DPY. William Logan, 2002, The Disappearing 'Asian' City, Protecting Asia's Urban Heritage in Globalising World. 2002.

2) Compendium of Good Practice, Urban Heritage in Indian Cities, NIUA, 2015. .

3) http://www.worldbank.org/en/news/feature/2011/09/22/india-urbaniza tion. .

4) WHITRAP, UNESCO, WHC, 2012. Application of the Historic Urban Landscape (HUL) Approach in China, (Report of the Expert Meeting organized by the World Heritage Institute of Training and Research for Asia and the Pacific (WHITRAP). 2012.

5) Cultural Heritage and Rapid Urbanisation in India, 2015, Newton-Bhava Fund, AHRC, Research Council UK, India. 2015. 